\title{
VADIAGEM E PRISÕES CORRECIONAIS EM SÃo PAULO: MECANISMOS DE CONTROLE NO FIRMAMENTO DA REPÚBLICA
}

\author{
Vagrancy and correctional prisons in São Paulo: control \\ mechanisms in the firmament of the Republic
}

\author{
Alessandra TeIXeIra, FERnANDO AFOnso SAlla E \\ MARIA GABRIELA DA SILVA MARTINS DA CUNHA MARINHO
}

http://dx.doi.org/10.1590/S2178-14942016000200004

Alessandra Teixeira é advogada, doutora em Sociologia pela USP (2012), com pós-doutorado em Ciências Sociais pela Faculdade de Filosofia e Ciências da UNESP/Marília (2015), e professora adjunta da Universidade Federal do ABC (UFABC) (alessandra.teixeira@ufabc.edu.br).

Fernando Afonso Salla é doutor em Sociologia pela USP (1997), pesquisador do Núcleo de Estudos da Violência da USP e professor do Programa de Mestrado Profissional Adolescente em Conflito com a Lei da Universidade Anhanguera de São Paulo (fersalla@usp.br).

Maria Gabriela da Silva Martins da Cunha Marinho é doutora em História Social pela USP e pesquisadora associada do Museu Histórico da Faculdade de Medicina da USP (MH-FMUSP).

Artigo recebido em 30 de abril e aprovado para publicação em 15 de junho de 2016. 


\title{
RESUMO
}

0 artigo discute o modo como se operou em São Paulo o controle e a repressão da vadiagem, categoria social forjada pelo discurso jurídico entre o final do século XIX e a primeira metade do XX, através de tecnologias de assujeitamento de indivíduos submetidos a formas de classificação e controle expressas em práticas policiais arbitrárias como as detenções correcionais. Para tanto, analisam-se sobretudo dados extraídos de relatórios policiais entre as décadas de 1930 e 1940, que indicam a sobreposição das medidas de controle social aos instrumentos jurídico-penais, opondo formas heterodoxas de gestão dos ilegalismos ao ciclo completo da punição.

PalaVras-CHAVE: vadiagem; repressão; São Paulo; detenções correcionais; Justiça Criminal.

\begin{abstract}
The article discusses how the control and repression of vagrancy, a social category created by the legal discourse between the late XIXth century and the first half of XXth century, were practiced in São Paulo, through technologies of subjection of individuals submitted to forms of classification and control expressed in arbitrary Police practices such as correctional detention. To do so, we analyse Police reports made in the 1930s and 1940s, which indicate the overlapping of measures of social control on legal and penal instruments, opposing heterodox forms of management of illegalisms to the entire punishment cycle.
\end{abstract}

KeYwORDS: vagrancy; repression; São Paulo; correctional arrests; criminal justice.

\section{RÉSUMÉ}

$L^{\prime}$ article discute la façon dont le contrôle du vagabondage, une catégorie sociale forgée par le discours juridique, a été pratiqué à São Paulo entre le XIXe siècle et la première moitié du XXe, à l'aide de technologies de sujétion des individus qui étaient soumis à des formes de classification et de contrôle exprimées dans les pratiques arbitraires de la Police telles que la détention correctionnelle. Pour ce faire, nous analysons les rapports de police des années 1930 et 1940, qui indiquent le chevauchement de mesures de contrôle social sur les instruments juridiques, en opposant des formes hétérodoxes de gestion des illégalismes au cycle complet de la punition.

MoTS-CLÉS: vagabondage; répression; São Paulo; arrestations correctionnels; justice pénale. 


\section{INTRODUÇÃO}

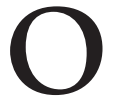

presente artigo discute a forma pela qual se operou na cidade de São Paulo o controle e a repressão da vadiagem, categoria social forjada pelo discurso jurídico entre o final do século XIX e a primeira metade do XX. Procuramos demonstrar como se engendraram tecnologias de assujeitamento de indivíduos submetidos a formas de classificação e controle que passaram a operar discursivamente tendo como mote o trabalho, sobretudo na experiência da capital paulista, embora experiências de outras cidades, como Rio de Janeiro, Santos, Campinas e Bragança tenham contribuído para matizar a análise.

Nessa perspectiva, o artigo identifica e analisa mecanismos e técnicas de vigilância, segregação e confinamento mobilizados pelo aparato jurídico e policial no período em torno da categoria vadiagem. Para tanto, foram utilizadas fontes primárias representadas, de um lado, pelos dados extraídos de Relatórios Policiais das décadas de 1930 e 1940. De outro, a análise se valeu dos processos criminais arquivados no Fundo Judiciário da Comarca de Bragança, documentação que recobre um largo espectro temporal. Nas fontes consultadas foram selecionados para o presente artigo dados relativos a processos criminais que incidiram na vigência do primeiro código penal republicano. ${ }^{1}$ Por fim, procedeu-se também à pesquisa de artigos publicados nos principais veículos de imprensa no período delimitado.

0 cotejamento dos dados oriundos das fontes apontadas, referentes às práticas policiais de controle da vadiagem, permitiu aduzir categorias discursivas construídas em torno da vadiagem, inserindo-a como alvo simbólico preferencial de controle e repressão no período. Ao mesmo tempo, a análise desse material permitiu compreender a forma como se estabeleceu a gestão diferencial dos ilegalismos, usando os termos de Michel Foucault (1975), através de práticas arbitrárias como as detenções correcionais, em detrimento do ciclo completo da punição, revelando assim a inexatidão do fluxo prisão-inquérito-processo, muito além de um pretenso rigor das formas de controle social (Teixeira, 2012).

\section{REPRESSÃo À VADIAGEM NA PRIMEIRA REPÚBLICA. VIGIAR, CONTROLAR E PUNIR OS LIBERTOS}

repressão aos vadios no Brasil tem uma longa história. As Ordenações do Reino, que
vigoraram por todo o período colonial, determinavam que os vadios, aqueles que não
tinham senhores ou meios de ganhar a vida, fossem presos e açoitados. A mesma legislação 
previa que vadios detidos em Portugal poderiam ser mandados para o Brasil. Contudo, na colônia, pessoas com algum lastro social seriam degredadas, uma vez que a formação social, polarizada entre proprietários de terras e escravos, dispunha entre esses dois grupos de uma camada composta de pequenos comerciantes e trabalhadores não-escravos, numa escala intermediária e matizada que abrigava indivíduos classificados (ou desclassificados) como vadios quando não conseguiam se inserir nas formas de existência do mundo colonial (Mello e Souza, 1982).

Entretanto, na tradição ibérica, e por consequência na formação social brasileira, jamais se desenvolveram as práticas comuns nos países do norte da Europa, as chamadas workhouses que confinavam os vadios, assim como os pequenos criminosos e todos aqueles que perambulavam pelas cidades, trilhas e caminhos, sem ocupação certa (Melossi e Pavarini, 1985). Tais instituições se organizavam pela imposição das práticas de trabalho e disciplina, premissas associadas ao mundo protestante emergente e a um ethos que no Brasil só tomaria corpo efetivo no final do Império e começo da República.

Assim, no Império, mendigos, vagabundos e ébrios eram frequentemente obrigados a assinar o termo de bem viver imposto pela autoridade policial. Obrigava-se o indivíduo a viver 'decentemente', ordenamento que embutia um objetivo corretivo, pois previa o confinamento para aqueles que rompessem com o termo. No Código de Processo Criminal de 1832, os termos de bem viver e o de segurança foram claramente fixados em relação ao Código de 1830, uma vez que o artigo 12 concedia ao juiz de paz dos distritos o poder de:

$\S 2^{\circ}$ Obrigar a assinar termo de bem viver aos vadios, mendigos, bêbados por hábito, prostitutas que perturbam o sossego público, aos turbulentos que por palavras ou ações ofendem os bons costumes, a tranquilidade pública e a paz das famílias.

$\S 3^{\circ}$ Obrigar a assinar termo de segurança aos legalmente suspeitos de pretensão de cometer algum crime, podendo cominar neste caso, assim como aos compreendidos no parágrafo antecedente, multa até trinta mil réis, prisão até trinta dias e três meses de casa de correção ou oficinas públicas.

A legislação assegurava, assim, ao juiz de paz a prerrogativa de impor ao indivíduo a pena que seria "repetida quantas forem as reincidências". Anos mais tarde, os poderes inicialmente concedidos ao juiz foram estendidos ao chefe de Polícia, delegados e subdelegados, como previsto na Lei n. 261 de 3 de dezembro de 1841. A pretendida correção de vadios, mendigos, bêbados e prostitutas, e o consequente confinamento na Casa de Correção de São Paulo, ${ }^{2}$ podem ser constatados, por exemplo, no termo de bem viver de 1872, arquivado no Fundo do Judiciário de Bragança, ${ }^{3}$ reproduzido a seguir: 


\section{Termo de Bem Viver (...)}

Aos vinte e três de abril de mil oitocentos e setenta e dois, nesta cidade de Bragança, em a casa da Câmara Municipal e sala das audiências do juízo, onde compareceu o Delegado de Polícia Antonio Pereira Paião Silveira, comigo escrivão interino de seu cargo e comparecendo também aí [ilegível] Maria de Jesus, Maria Rosa da Conceição e Maria Joaquina de Oliveira que foram notificadas para assinarem termo de bem viver por vadias, pelo dito delegado Ihes foi declarado que elas tinham sido notificadas para esse fim, e as convidava a assinarem termo de bem viver, evitando assim os processos que em tais casos se costuma fazer, inquirindo-se testemunhas etc., para o que já estavam presentes as testemunhas notificadas, e por elas foi dito e declarado que estavam prontas a assinar dito termo, independente de processo, obrigando-se por tanto pelo presente a empregarem-se dentro do prazo de quinze dias como criadas domésticas em alguma casa de família honesta, vivendo do mesmo modo ou qualquer outro emprego honesto não podendo depois de empregadas sem um motivo justificativo saírem ou desempregarem-se, salvo incontinenti tornarem-se a empregar; e o delegado cominou-lhes a pena de três meses de Casa de Correção pela infração de qualquer destas obrigações que irão cumprir na Capital de São Paulo. Do que para constar fiz este termo em que a seus rogos por não saberem escrever assina José Antonio Barreto... ${ }^{4}$

Em tal conjuntura, a perseguição e repressão da vadiagem podem ser entendidas como uma das formas de controle que se realizava sobre a massa de indivíduos aparentemente heterogênea (bêbados, prostitutas) que estava, porém, umbilicalmente conectada ao fenômeno da escravidão, organizador da estrutura social da colônia e do império. Aqui reside certa peculiaridade da experiência brasileira, na sua tentativa de realizar aquilo que Koerner (2001; 2006) descreveu como "o impossível panóptico tropical escravista", ou seja, o esforço de incorporar as técnicas de controle, vigilância e punição, apoiadas na estrutura econômico-social capitalista e no trabalho livre, à estrutura agrário-escravista.

A figura do escravo assumiu a personificação desse paroxismo: excluído da ordem jurídico-civil por ser coisa e não sujeito de direitos, mas ao mesmo tempo incluído na ordem jurídico-penal, sujeito a pena ou a prisão pelo continuum dos castigos cruéis que orbitavam das senzalas às masmorras. A abolição da escravatura, em 1888, promoveria uma primeira fricção nesse processo ao realizar finalmente "a separação entre o trabalhador e sua força de trabalho", nos dizeres de Chalhoub (1986:65). Ainda assim, por um lado, estabeleciam-se mecanismos para impor o trabalho ao trabalhador, agora livre. De outro, asseguravam-se novas formas de controle a um contingente de ex-escravos libertos.

É nesse contexto, portanto, que se instala a intensa mobilização das elites com 0 objetivo de criar dispositivos para intensificar a perseguição e a repressão à vadiagem. Assim, 
poucos dias após a Abolição em 1888 foi apresentado na Câmara dos Deputados pelo então Ministro da Justiça, Ferreira Vianna, o Projeto de repressão à ociosidade, com a finalidade principal de controlar os libertos, cuja ociosidade passou a ser vista como ameaçadora à ordem e à lei, leia-se, à propriedade (Chalhoub, 1986). As intensas discussões que sucederam à análise desse projeto e de outros similares, apresentados simultaneamente na Câmara dos Deputados, visavam à construção de um sistema de perseguição e controle das classes ditas perigosas, com a justificativa formal de promover a correção moral da ociosidade e suas degenerescências, impondo uma ética regeneradora erigida em torno do trabalho forçado nos institutos correcionais.

Fausto (1984) e Bretas (1997), em seus estudos sobre a Primeira República nas cidades de São Paulo e do Rio de Janeiro, respectivamente, já haviam destacado como a vadiagem constituiu o principal alvo de controle social do período. No caso de São Paulo mais precisamente, é certo que a vadiagem correspondia à versão em negativo do projeto de nação moderna e ordeira que naquele momento as elites pretendiam ver construído, sob a liderança dos republicanos do estado. Cândido Nazianzeno Motta, homem influente na política da Primeira República em São Paulo, quando promotor de justiça, no seu relatório ao procurador geral sobre a situação da justiça criminal em São Paulo, sustentava que a vadiagem era o primeiro degrau para todos os delitos. Para ele, "é justamente nesta Capital [São Paulo] que deve haver maior rigor na repressão da ociosidade e também da mendicidade, porque nossos vagabundos são verdadeiros degenerados, pois não temos causas econômicas e morais que os justifiquem" (Motta, 1895: 10).

Denunciar, perseguir e controlar a vadiagem, além de referir à modulação de comportamentos das categorias sociais alvo do controle social, também respondia ao conjunto de transformações que o país atravessava, expresso na emergência do trabalho livre, da nova ordem econômica e do processo de urbanização.

Assolada pelo rápido crescimento econômico do começo do século XX, a disciplinarização das classes populares para o trabalho tornava-se, portanto, imperiosa em São Paulo, imposição para a qual contribuía a noção de progresso. Daí a necessidade e o empenho em agravar penas e efetivamente criminalizar a conduta do desocupado, objetivando dessa forma, e de modo pioneiro, a pena como regeneração moral. 0 Código Penal de 1890 abrigou esse mecanismo peculiar de perseguição às camadas populares representadas sobretudo na figura do liberto. E criminalizou desse modo o vadio e capoeira ${ }^{5}$ no mesmo tipo penal, não restando dúvida sobre o alvo a quem se dirigia o projeto punitivo da República, sob as vestes da correção moral pelo trabalho, como pode ser aferido pelo trecho do Código reproduzido a seguir: 
CAPITULO XIII, DOS VADIOS E CAPOEIRAS

Art. 399. Deixar de exercitar profissão, ofício ou qualquer mister em que ganhe a vida, não possuindo meios de subsistência e domicílio certo em que habite; prover a subsistência por meio de ocupação proibida por lei, ou manifestamente ofensiva da moral e dos bons costumes:

Pena - de prisão celular por quinze a trinta dias.

$\S 1$ ㅇ Pela mesma sentença que condenar o infrator como vadio, ou vagabundo, será ele obrigado a assinar termo de tomar ocupação dentro de 15 dias, contados do cumprimento da pena.

$\S 2$ Os maiores de 14 anos serão recolhidos a estabelecimentos disciplinares industriais, onde poderão ser conservados até a idade de 21 anos.

Art. 400. Se o termo for quebrado, o que importará reincidência, o infrator será recolhido, por um a três anos, a colônias penais que se fundarem em ilhas marítimas, ou nas fronteiras do território nacional, podendo para esse fim ser aproveitados os presídios militares existentes.

Parágrafo único. Se o infrator for estrangeiro será deportado.

Nota-se que o Código de 1890 reconfigurou o controle e a repressão à vadiagem em relação ao Código do Império, repaginando o termo de bem viver agora consubstanciado em termo de tomar ocupação, obrigando os vadios a procurar emprego lícito. Havendo a quebra do termo, o indivíduo poderia ser recolhido a colônias correcionais. Assim, o termo de tomar ocupação tornou-se ainda mais rigoroso, e o Código de 1890 previa a criação de uma rede de instituições para abrigar aqueles que o quebrassem, fossem adultos ou menores. 0 controle sobre os vadios e vagabundos por meio da imposição ao trabalho se tornou bastante explícito, inclusive pela estruturação dessa rede de instituições destinadas a coibir, conter, controlar e modelar esse conjunto de indivíduos.

Em São Paulo, em decorrência do Código, foram criadas instituições como o Instituto Disciplinar para menores, o Manicômio Judiciário, anexo ao Hospital do Juquery em Franco da Rocha, o Asilo dos Inválidos no bairro do Guapira, a Colônia Correcional na Ilha dos Porcos, locais destinados a segmentos sociais que não poderiam mais permanecer no meio urbano, engendrando-se a lógica de higienização do espaço público pela remoção dos indesejáveis. ${ }^{6}$ Se no Asilo dos Inválidos ou mesmo no Manicômio o trabalho tinha um papel secundário na condução do cotidiano institucional, pelas características dos internos, nas demais que foram criadas ele tinha um papel central.

No entanto, embora o estatuto jurídico e a punição da vadiagem tenham se tornado mais severos e o discurso regenerador de matriz positivista estivesse fortemente presente tanto nas estruturas jurídicas e burocráticas do Estado (Alvarez, 2003) como nos projetos das 
instituições modelares criadas no período como o Instituto Disciplinar e a Penitenciária do Estado, ${ }^{7}$ o controle das classes populares se realizava pelos mecanismos de aplicação da lei e as detenções correcionais eram mais significativas que o ciclo completo da punição.

\section{Arbítrios de LONGA DURAÇÃO}

s detenções correcionais consistiram em práticas policiais arbitrárias que vigoraram no
sistema de controle social e repressão criminal brasileiro do Império até meados dos anos 80 do século XX. Além de se caracterizarem como instrumento privilegiado, aparentemente voltado para a manutenção da ordem pública pelas forças policiais, as autointituladas práticas correcionais não se voltavam para condutas criminais propriamente ditas, ou mesmo para o cometimento de contravenções. Destinavam-se, antes, a determinados tipos sociais e eram operacionalizadas à margem dos termos legais e à revelia de uma acusação formal, sem a formação do devido processo (Teixeira, 2012).

João Mendes de Almeida Jr. comenta que, no Império, as prisões à revelia da lei eram tantas que o ministro da Justiça, por meio de Aviso Circular de 2 de janeiro de 1865, pedia aos presidentes de província para coibir os abusos nas prisões preventivas e nas "prisões pelo motivo vago de investigações policiais" por ele consideradas "manifestamente ilegais". Observa que nova circular, de 3 de julho de 1889, aos mesmos destinatários, reiterava que "o atual direito não comporta o abuso que ainda perdura de prisões para averiguações policiais" [grifos no original] (Almeida Jr., 1901: 315-318, vol. I). Não obstante a flagrante ilegalidade dessas prisões, sua utilização esteve plenamente difundida e incorporada à dinâmica social rotineira, inclusive de instituições do poder judiciário.

É possível dizer que em torno da permanência dessa prática remota de controle residiam os modos precisos de desativação da lei pelos quais o Estado realizava sua economia diferencial de ilegalismos. Pois era através dela que se elegiam desde as condutas (em primeiro lugar a vadiagem, mas também o alcoolismo, o escândalo) até os personagens (o malandro, a prostituta) que se pretendia controlar, assim como se perfazia o jogo contínuo de extorsões e transações pelo qual o aparelho policial se imiscuía no campo poroso do ilegalismo. As prisões correcionais constituíam precisamente a antítese do ritual da punição moderno, flagrado por Foucault (1975), no advento das sociedades disciplinares. Na experiência nacional, a prática da detenção correcional se converteu no instrumental de controle através do qual o aparelho policial pôde gerir os ilegalismos, subtraindo do sistema de justiça essa prerrogativa (Teixeira, 2012).

Assim, embora a Colônia Correcional da Ilha dos Porcos ${ }^{8}$ (mais tarde designada Ilha de Anchieta) houvesse entrado em funcionamento em 1907, justamente para internar os 
condenados vadios, no intuito de discipliná-los para o trabalho, uma parcela relativamente pequena desses indivíduos era remetida para a instituição. Nesse sentido, o relatório do Chefe de Polícia de 1939 aponta, por exemplo, que em 10 de outubro 1914 a Lei oํ 1.845 transferiu a referida colônia para Taubaté, ${ }^{9}$ sob o argumento de que a Colônia da llha dos Porcos não cumpria sua finalidade, uma vez que, não obstante o custo de sua manutenção, "apenas 80 vadios lá se encontravam recolhidos". Embora o estatuto jurídico e a punição da vadiagem tenham se tornado mais severos, sua perseguição manteve-se adstrita ao espectro do controle cotidiano pela atividade policial, consistindo no grande objeto das detenções correcionais, a despeito do baixíssimo percentual de inquéritos e processos instaurados. ${ }^{10}$

Exemplos desse descompasso podem ser verificados nos números das prisões efetuadas pela polícia e dos inquéritos efetivamente instaurados. Ao apresentar seu relatório relativo ao ano de 1928, o delegado Juvenal Piza, da Delegacia de Costumes e Jogos, indicava que haviam sido instaurados 107 inquéritos no ano. Porém as prisões efetuadas tinham sido 805, como mostram os dados abaixo:

Número de prisões, 805

Atos imorais, 10

Escândalos, 214

Desordens, 43

Averiguação, 133

Curandeiros, 29

Cartomantes, 13

Feiticeiros, 29

Jogos e alabamas, 38

Tóxicos, 30

Caftens, 21

Pederastas, 27

Ambulantes, 7

Motivos diversos, 211

Total, $805^{11}$

Há que se destacar nos dados acima o elevado número de "motivos diversos", ou seja, mais de $25 \%$ de prisões sem uma especificação clara, ao lado de 214 sob o item "escândalos", igualmente difuso. Destaque-se, ainda, 133 prisões para averiguação (a mais arbitrária espécie de detenção correcional) que representaram $16,5 \%$ do total. Deve-se ressaltar, também, o amplo e variado espectro de tipologias alcançado pela ação policial, ao qual ainda se agregou o ambíguo tópico Motivos Diversos. 


\section{VAdiagem, PROSTITUIÇÃO E DESORDENS URBANAS}

P

arece não haver dúvida de que a vadiagem ocupou um lugar central na gestão da população urbana, na lógica de seu controle numa sociedade que saía do trabalho escravo e tinha uma forte expansão da economia do café e de um emergente ciclo de industrialização. Souza (2009), na sua análise sobre a Polícia Civil de São Paulo na Primeira República, apresenta detalhadamente as práticas policiais adotadas em relação à repressão contra a vadiagem e indica as constantes preocupações do aparato policial com as conexões da vadiagem com os jogos, as casas de prostituição, a mendicância e os menores que perambulavam pelas ruas. Juntamente com os ébrios, constituía-se, para a polícia, um espectro de desordens urbanas que seriam passíveis de um estreito controle sobre o cotidiano. Foram esses sujeitos e territórios que proporcionaram uma intensificação e cristalização de práticas policiais de apreensão correcional, ou para averiguação, que se mantiveram nas esmaecidas margens da ilegalidade.

Um exemplo dessas formas de intervenção policial na desordem urbana, sem um fundamento legal claro, pode ser lido no jornal O Combate do dia 22 de novembro de 1922, que trouxe uma série de conflitos armados na zona de prostituição (Cidade Nova), envolvendo marinheiros, soldados do exército e policiais. Tiros, correrias, "verdadeira fuzilaria" entre os três grupos por dois dias. Vários feridos. E o desfecho: o delegado prendeu "todas as mulheres residentes nas ruas Pinto Figueiredo, Affonso Cavalcanti, Visconde Duprat e adjacências, teatro dos últimos conflitos. Há perto de cem mulheres presas". ${ }^{12}$

Uma verdadeira "cruzada" contra os botequins localizados nas ruas do chamado baixo meretrício ocorria nesse período em Santos. Tais locais se apresentavam, segundo o discurso moralizador da época, como "espeluncas que servem unicamente para ajuntamento de desordeiros e desocupados que ali passam a noite embriagando-se e promovendo desordens". ${ }^{13}$

Ao longo dos anos 1920 os aparatos policiais mobilizaram-se para retirar das áreas mais centrais das cidades as casas de tolerância, ${ }^{14}$ sempre apontando as desordens que provocavam com o trânsito de sujeitos vadios, desordeiros etc. Apesar das iniciativas policiais para tanto, ao que parece nem sempre as ações foram bem-sucedidas no curto prazo. Em 1928, havia em São Paulo 553 casas de tolerância e 235 rendez-vous, de acordo com o relatório de Juvenal Piza, delegado de Costumes e Jogos da capital. Segundo ele, a Delegacia estava "afastando das ruas centrais e movimentadas os prostíbulos ali existentes, encaminhando-os a locais menos movimentados". ${ }^{15}$ Embora tenha motivado constantes intervenções policiais, tratava-se apenas de um deslocamento espacial das "desordens urbanas" para áreas mais distantes, mas nem por isso menos submetidas ao controle da Polícia. 


\section{Menores Sitiados: VAdios, Delinguentes E PERVERTIDOS}

D esde o início da República, os chamados menores eram motivo de preocupação das autoridades policiais e foram também incluídos naqueles grupos que mereceriam um controle mais estreito, sobretudo os taxados de vadios, delinquentes ou pervertidos. A condição de abandono levava à vadiagem dos menores, que era vista como o primeiro degrau para o ingresso numa vida de crime. Depois de serem criadas duas das instituições acima mencionadas - o Instituto Disciplinar na Capital e o Instituto Correcional em Taubaté -, na década de 1920 esse rol foi ampliado com a criação, em 1924, do Instituto Disciplinar de Mogi-Mirim. Nesse mesmo ano, foi criado em São Paulo o Juizado de Menores. Até a entrada em vigor do Código de Menores, em 1927, o campo de atuação da polícia sobre menores que vadiavam ou cometiam pequenos furtos na cidade era bastante alargado e também opaco quanto aos recursos legais que o revestiam, uma vez que muito da regulamentação da atuação policial se dava por meio de decretos ou determinações internas à própria polícia.

Quando da criação do juízo de menores em 1924, houve uma maior interferência e controle dos juízes de menores sobre as atividades policiais em relação aos procedimentos para a internação dos menores encontrados nas ruas como abandonados, delinquentes ou pervertidos. 0 Decreto n. 3828, de 25 de março de 1925, que regulamentou o Juízo de Menores, trazia em detalhes essas qualificações dos menores que em parte já estavam estabelecidas nas rotinas policiais e mesmo dos juízes. No artigo 2ํㅜ o abandono poderia se dar por múltiplas razões, como não terem os menores "habitação certa, nem meios de subsistência, por serem seus pais falecidos, desaparecidos ou desconhecidos, ou por não terem tutor ou pessoas sob cuja guarda vivam na ausência dos pais" (Item I). Ou então por indigência, enfermidade ou incapacidade dos pais ou tutores. Mas era em relação à definição de pervertidos e delinquentes que o próprio juízo, com essa regulamentação, tornava ainda mais amplo os casos de intervenção policial na gestão dos menores.

Artigo $3 .^{\circ}$ - Consideram-se pervertidos os menores vadios, mendigos e libertinos.

$\S 1 .^{\circ}$ - São vadios os que, tendo deixado, sem causa legitima, o domicilio do pai, mãe, tutor, guarda, ou os lugares onde se achavam colocados por aquele a cuja autoridade estavam submetidos ou confiados, são encontrados habitualmente a vagar pelas ruas ou logradouros públicos, sem que tenham meio de vida regular, ou tirando seus recursos de ocupação imoral, proibida ou provadamente insuficiente.

§ 2. - São mendigos os que habitualmente pedem esmola, para si ou para outrem, ainda que este seja seu pai ou sua mãe ou pedem donativos sob pretexto de venda ou oferecimento de objetos. 
§ 3. - - São libertinos os que habitualmente:

a) na via pública perseguem ou convidam companheiros ou transeuntes para a pratica de atos imorais;

b) se entregam à prostituição em seu próprio domicílio, ou vivem em casa de prostituta, ou frequentam casa de tolerância, para praticar atos imorais;

c) são encontrados em qualquer casa ou lugar, praticando atos imorais com outrem;

d) vivem da prostituição de outrem. ${ }^{16}$

Os menores delinquentes foram definidos no artigo 60 entre aqueles que, "tendo mais de 14 e menos de 18 anos de idade, forem indiciados autores ou cúmplices de facto qualificado pela lei como crime ou contravenção".

Nas primeiras décadas do século XX são muito escassas as informações sobre infrações cometidas por meninas menores. As ocorrências de que se tem mais notícias estavam relacionadas ao abandono de uma forma geral e à prostituição. De qualquer modo, uma das rotinas da polícia quando da apreensão de meninas menores nos circuitos de prostituição era o encaminhamento delas por parte do delegado para o Asilo do Bom Pastor, ordem religiosa católica que mantinha casas para órfãs, visando principalmente à correção de delinquentes e prostitutas. Fonseca (1988) menciona que nos anos 1920 as autoridades policiais apontavam a lotação máxima do Asilo, mas depois da criação do Juízo de Menores, em meados da década, essas internações naquele Asilo passaram a ser feitas pelo juiz.

\section{ERA VARgas EM SÃo PAulo: CONTROLE dos VADIOS EM DETRIMENTO DA PUNIÇÃO}

$\mathrm{N}$ o plano econômico e urbano, a crise de 1929 produziu efeitos no país que se prolongaram até o Estado Novo, provocando o crescimento considerável de pessoas sem emprego ou ocupação estável. Como resultado da intensificação da perseguição à vadiagem nos anos Vargas, haveria uma maior especialização no interior do aparelho policial com vistas a melhor qualificar e controlar o contingente difuso da vadiagem, que se diluía em categorias sociais diferenciadas. Em 1935, por exemplo, a Delegacia de Vigilância e Capturas, que exercia desde 1926 subsidiariamente funções de capturas, teria sua competência estendida pelo Decreto 7223 de 21 de junho para atuar precipuamente na prisão de menores e mendigos, separando-os entre falsos ou verdadeiros, sendo os falsos enviados à Delegacia de Repressão à Vadiagem para que fossem, em tese, processados. 
No Código Penal de 1890 (artigos 391 a 398), os mendigos e ébrios eram colocados como alvos de controle e punição. Assim como o trabalho estava na lógica do controle sobre a vadiagem, aqueles artigos do Código procuravam igualmente punir os que eram capazes para o trabalho, mas se dedicavam à mendicância. Legislação posterior como, por exemplo, o Decreto n. 6994, de 16 de junho de 1908, em relação aos mendigos, e o Decreto n. 4294, de 6 de junho de 1921, em relação aos ébrios, ampliaram as formas e tempos de punição. Tais arranjos na legislação mostravam a proximidade, por um lado, na forma de gestão via o controle policial de mendigos e vadios, e por outro, a busca da sujeição pelo trabalho.

É certo que as categorias verdadeiros e falsos empregadas para os mendigos não estavam contidas na legislação penal, mas eram formulações que operacionalizavam as ações policiais. E ainda, no bojo da separação entre verdadeiros e falsos mendigos estava um esforço para romper com certa tolerância com a mendicância que se praticava até então, em muito alimentada pela importância do papel da Igreja católica nas práticas de assistência social que eram delegadas pelo aparelho estatal ainda incipiente. A atividade discricionária e subjetiva de "distinguir" entre os verdadeiros e falsos necessitados se tornara, pelo Decreto no 7223/39, atribuição dos agentes policiais, na perspectiva de substituir a ética caritativa pela ética do trabalho, mesmo sem qualquer critério objetivo para operar a referida diferenciação no interior da miséria social em que se encontravam os alvos do controle.

Ao mesmo tempo, a população da cidade de São Paulo crescia em ritmo significativo, resultado também de um afluxo contínuo de migrantes, elementos que, somados à crise econômica instalada, contribuíram para um quadro de subempregos, desempregos e pobreza urbana. Impondo o rigor da prisão aos desocupados e aos menores, a atividade de perseguição e detenção da vadiagem, até então subsidiária no aparelho policial, foi erigida para posição de destaque, e com ela novas estratégias de controle e segregação desse contingente, como se depreende da afirmação do chefe de polícia no Relatório de 1936: "Desse modo, a antiga e pequena 'turma de menores' transformou-se numa importante secção destinada ao policiamento de menores, vadios e abandonados" (RELGAB, 1936: 13). ${ }^{17}$

Essa atividade parece ter sido levada a sério pelas forças policiais, tendo-se procedido a nada menos que 2.228 detenções de mendigos no ano de 1935, dos quais 1.174 foram tidos como falsos e enviados para a Delegacia Especializada, e os demais distribuídos entre o Abrigo de Vila Mascote e a Colônia Agrícola de Bussocaba, além de poucos reenviados às suas famílias em outros Estados. A existência dessas duas instituições assinala as formas de cooperação entre o aparato policial, judiciário e assistencial privado - no caso católico -, no gerenciamento de tais grupos. As duas instituições foram criadas pela Assistência Vicentina, e 
a de Vila Mascote recebeu a denominação de "Cidade dos Pobres". A Delegacia de Vigilância e Capturas destinava para lá os mendigos "verdadeiros". ${ }^{18}$

No ano de 1936, embora reduzidas pela metade, provavelmente como resultado da diferenciação da mendicância criada pelo decreto mencionado, as detenções de mendigos ainda mantiveram um patamar elevado, com 1.026 apreensões. E a mesma determinação ostentada pela Delegacia de Repressão à Vadiagem em perseguir e deter os mendigos pôde ser verificada em relação aos menores. 0 total de apreensões de menores no ano de 1935 na capital foi de 1.886, o que demonstra um especial empenho policial na sua perseguição (RELGAB, 1936). 0 resultado mais evidente desse contexto de intensificação da perseguição à vadiagem pode ser verificado pelos dados de prisões correcionais efetuadas pela Delegacia de Repressão à Vadiagem nos anos de 1934, 1935, 1936 e 1939, conforme expressa a tabela abaixo.

Tabela 1. Detenções correcionais efetuadas pela Delegacia de Repressão à vadiagem em números absolutos e segundo taxas por 100 mil hab. Capital nos anos 1934, 1935, 1939

\begin{tabular}{lcccc}
\hline Detenções correcionais por vadiagem & 1934 & 1935 & 1936 & 1939 \\
Número absoluto & 916 & 1.363 & 1.242 & 1.520 \\
Taxa (por 100 mil habitantes) & 86,2 & 123,1 & 107,9 & 118,5
\end{tabular}

Fonte: Relatório do Gabinete de Investigações relativo ao de 1936. Secretaria de Negócios da Segurança Pública (RELGAB de 1936) e Relatório das atividades da Polícia Civil no exercício de 1939, apresentado pelo Chefe de Polícia ao interventor do Estado (RCPPOLSP, 1939).

Nota-se um aumento importante das detenções por vadiagem realizadas pela delegacia especializada entre os anos de 1934 e 1935, quando a taxa de detidos saltou de 86,2 para 123,1, decrescendo em 1936 e fechando a década com 118,5 detidos por 100 mil habitantes. De todo modo, entre 1934 e 1939, o número de prisões por vadiagem aumentou 60\%, ao passo que a população ao longo da década de 1930 teve um crescimento de $50 \%$.

É certo, contudo, que o número de prisões correcionais por vadiagem nos anos mencionados não inclui as detenções de falsos mendigos realizadas pela Delegacia de Vigilância e Capturas, o que certamente subdimensiona o controle social voltado para o imenso contingente cunhado como vadio. Desse modo, tomando-se a cifra de falsos mendigos presos pela Delegacia de Vigilância e Capturas em 1935 (1.174) e somando-se com as detenções por vadiagem realizadas pela Delegacia especializada no mesmo ano (1.363), tem-se a visão de como era elevada a perseguição aos vadios e como dela se ocupava a polícia, chegando a perfazer um total de 2.537 pessoas presas por vadiagem no ano de 1935, o que corresponde uma taxa de 229,2 por 100 mil habitantes. 
Não obstante o alto número de detenções, a dinâmica judicial não era acionada para o processamento dos indivíduos detidos, similarmente ao período analisado por Fausto (1984), como se vê nas tabelas 2 e 3 a seguir.

Tabela 2. Inquéritos instaurados e remetidos ao Fórum Criminal pela Delegacia de Repressão à Vadiagem na Capital - 1934 a 1936

\begin{tabular}{lccc|}
\hline & & Anos & 1936 \\
\hline $\begin{array}{l}\text { Mrt. } 399 \\
\text { (vadiagem ou capoeiragem) }\end{array}$ & 1934 & 1935 & 244 \\
\hline $\begin{array}{l}\text { Art.400 } \\
\text { (reincidência por vadiagem } \\
\text { ou estelionato) }\end{array}$ & 285 & 320 & 164 \\
& 36 & 97 & 113 \\
\hline $\begin{array}{l}\text { Furto } \\
\text { Expulsão }\end{array}$ & 4 & 32 & 26 \\
\hline Dano, desordem, embriaguez etc. & 15 & 26 & 27 \\
\hline Outros & -10 & 5 & 2 \\
\hline Total & 350 & 4 & 28 \\
\hline
\end{tabular}

Fonte: Relatório do Gabinete de Investigações relativo ao de 1936. Secretaria de Negócios da Segurança Pública (RELGAB de 1936).

Tabela 3. Inquéritos remetidos ao Fórum Criminal pela

Delegacia de Repressão à Vadiagem ano 1939

\begin{tabular}{lc} 
Crime & Inquéritos \\
\hline Estelionato & 97 \\
Apropriação Indébita & 9 \\
Outros & 16 \\
Total & 122 \\
Fonte: Relatório das atividades da Polícia Civil no exercício de 1939, apresentado pelo Chefe de Polícia ao \\
interventor do Estado (RCPPOLSP, 1939).
\end{tabular}

Em 1939, houve uma redução ainda maior no número de inquéritos remetidos, 122, menos de $10 \%$ do total das prisões efetuadas pela delegacia especializada. É interessante observar também que os motivos das detenções correcionais relativos a 1939 expressos nas tabelas 4 e 5 revelam a diversidade de perfis e condutas sob a rubrica vadiagem. Cabe assinalar que, a partir desse período, a figura do vadio irá desdobrar-se em diferentes condutas e personagens, que continuarão a orbitar pela mendicância e pequenos furtos, mas alcançarão tal caracterização que deixarão de ser apenas tipos para compor a ambiência social da época. 
Tabela 4. Detenções correcionais efetuadas pela Delegacia de Repressão à Vadiagem segundo motivo na Capital - 1939

\begin{tabular}{lc|} 
Motivos & Detenções \\
\hline Para Averiguação & 975 \\
Vigaristas & 235 \\
Punguistas & 215 \\
\hline Micheiros & 95 \\
\hline TOTAL & 1.520
\end{tabular}

Fonte: Relatório das atividades da Polícia Civil no exercício de 1939 apresentado pelo Chefe de Polícia ao interventor do Estado (RCPPOLSP, 1939).

A grande maioria das prisões correcionais, como se depreende da Tabela 4, já se referia à modalidade para averiguação, a subespécie mais explícita do arbítrio policial. Não por acaso, das 975 prisões para averiguação efetuadas pela Delegacia de Repressão à Vadiagem, não houve uma sequer que tenha resultado em instauração de inquérito policial. Quanto aos demais motivos, aparecem o vigarista, correspondendo a 235 detenções, o punguista, a 215, e em menor representatividade o micheiro. ${ }^{19}$ Observe-se que não são os crimes ou contravenções que dão nome às prisões, mas os autores, já cunhados com a designação de seus personagens. E não é menos banal que tanto o vigarista como o punguista e o micheiro, embora encerrassem condutas tipificadas como crimes patrimoniais (o estelionato e o furto), constituíssem uma categoria à parte dos estelionatários e furtadores, não sendo contabilizadas suas prisões nas estatísticas das respectivas delegacias especializadas de Falsidades e de Furtos.

Na verdade, ambos caracterizavam tipos sociais que diziam respeito a um modo de vida, para além das condutas criminais. Eram vistos como ameaça à ordem não exatamente pelas condutas, mas por estarem implicados em uma ambiência social que podia ser a zona de meretrício, as casas de jogo e demais espaços em que se inscrevia a boemia paulistana do período.

Tabela 5. Detenções policiais e correcionais no Estado segundo principais motivos 1938, 1939, 1940 e 1943

\begin{tabular}{|lrrrr|}
\hline Motivos & 1938 & 1939 & 1940 & 1943 \\
\hline Alcoolismo & 11.853 & 12.598 & 12.281 & 3.147 \\
\hline Desordem & 6.715 & 6.880 & $*$ & 4.105 \\
Vadiagem & 1.378 & 1.376 & 933 & 815 \\
\hline Desobediência & 796 & 863 & $*$ & 1.040 \\
\hline
\end{tabular}

* não informa

Fonte: A Estatística policial-criminal do Estado de São Paulo, 1939, 1940, 1943. Departamento Estadual de Estatística. Serviço de Estatística policial 
Assim, nos anos seguintes, o ethos moralizador de que se revestiam as práticas de controle se deslocaria paulatinamente da vadiagem para outras categorias como desordem, para recair, enfim, sobre aquela que melhor resumia o papel das detenções correcionais na gestão dos ilegalismos: as prisões para averiguação.

\section{CONSIDERAÇÕES FINAIS}

$\mathrm{O}$ artigo buscou demonstrar a posição estratégica da categoria social vadiagem nas práticas normalizadoras no país, da Primeira República à Era Vargas. Analisa como o fim da escravidão promoveu o esforço para se erigir o trabalho, a família e uma noção particularíssima de ordem como centro da dinâmica social, o que impôs, em decorrência, um acento disciplinador e normalizador sobre práticas de controle que intensificaram a perseguição de categorias que representavam o avesso desse projeto: a desocupação, a vadiagem, o ócio, enfim, o variado e amplo "arco da desordem".

Contudo, esse projeto pretensamente disciplinador guardou diferenças importantes em relação a outras formas de vigilância e punição que se faziam presentes desde o início do século XIX do outro lado do Atlântico. Na experiência nacional, a sobreposição de práticas ilegais de detenção, sempre precárias e transitórias, sobre os mecanismos duradouros da prisão por condenação para "correção moral", indicou muito mais um jogo particularíssimo de transição entre legalidade e ilegalidade, pelas instituições de controle, do que um projeto disciplinador acabado. Esse jogo pode ser expresso na relevância das práticas de controle da vadiagem pelas prisões correcionais e prisões para averiguação, amparado pelo escasso número de inquéritos e processos instaurados para investigar e punir vadios e congêneres, revelando o descompasso entre o discurso regenerador corretivo, a prática das prisões arbitrárias e a ausência de sua correlação ao universo jurídico-penal.

\section{Notas}

1 A documentação utilizada decorre do projeto A Modernização do Sistema de Justiça Criminal na Região de Bragança Paulista, 1890-1940, que selecionou em torno de 534 processos criminais. 0 projeto foi desenvolvido com recursos do CNPq no Fundo do Poder Judiciário da Comarca de Bragança Paulista, documentação que se encontra depositada no Centro de Documentação e Apoio à Pesquisa em História da Educação (CDAPH) da Universidade São Francisco (USF). Projeto CNPq - Edital MCT/CNPq - 02/2006 - Universal Processo 475915/2006-2.

2 Sobre a Casa de Correção de São Paulo, que começou a funcionar em 1852, consultar Salla (1999) e Gonçalves (2013).

3 Conferir: CNPq-Relatório Final Projeto A Modernização do Sistema de Justiça Criminal na Região de Bragança Paulista, 1890-1940. 
4 Livro para Termos de Bem Viver (1861-1880), CDAPH. Em outros termos pesquisados, também aparecia o convite para que o documento fosse assinado, evitando arrolamento de testemunhas. Persistia também a ameaça, em caso de quebra do termo, de envio para a Casa de Correção na capital. Praticamente em todos os casos registrados no Livro os acusados eram analfabetos e o termo era assinado a "rogo" por outra pessoa.

5 Com relação à capoeiragem, vale destacar que em São Paulo sua representatividade foi muito menor do que no Rio de Janeiro, onde a perseguição às maltas de capoeiras remete a meados do século XIX, correspondendo, segundo Misse, a grande parte dos incriminados por vadiagem, lembrando ainda que se trata de uma das origens de representações sobre a malandragem carioca (Misse, 2006: 153).

6 Sobre as instituições criadas em decorrência do Código de 1890 ver Alvarez et al. (2003).

70 Instituto Disciplinar foi criado em 1902 (Lei n. 844, de 10 de outubro) para receber menores de 9 a 14 anos na condição de abandonados, pequenos vadios e viciosos entre 14 e 21 anos condenados por vadiagem. O processo de concepção e criação da Penitenciária do Estado (que remonta também ao final do século XIX, não obstante sua inauguração ter ocorrido apenas em 1920) foi analisado por Salla (1999). Tal projeto representou o ideário criminológico de regeneração de criminosos para o qual confluíram preocupações próprias da área policial-judiciária com as inquietações derivadas do meio político da época.

8 A Colônia Correcional da Ilha dos Porcos foi criada pela Lei 844, de 14 de outubro de 1902, foi regulamentada pelo Decreto n. 1.438, de 14 de fevereiro de 1907, e em março desse ano recebeu a primeira leva de 24 condenados (Fonseca, 1988:66).

9 Em 1928, pela Lei 2.347, o estabelecimento retornaria para a llha dos Porcos, retomando a designação original de colônia correcional. Em 1931, no início da era Vargas, o Decreto 5.080 de 26 de junho a transformou em presídio político. No entanto, em 1933, o Decreto 6.245 de 29 de dezembro reorganizou a estrutura policial do Estado e devolveu a sua destinação original de colônia correcional agrícola. Em 1941, foi transformada em Instituto Correcional para receber adultos e menores perigosos e indisciplinados de todo o sistema. Em 20 de junho de 1952, foi destruída e depois desativada após um violento motim, sendo formalmente extinta em 1955.

10 No Rio de Janeiro, a situação era bastante similar. Segundo Bretas (1997), no ano de 1928, por exemplo, das 472 prisões por vadiagem na cidade do Rio de Janeiro apenas 61 resultaram em processos criminais.

110 Relatório da Delegacia de Costumes e Jogos foi publicado na íntegra no dia 23/01/1929, no jornal Correio Paulistano, p. 4. Acessível na Hemeroteca Digital da Biblioteca Nacional: bndigital.bn.br/hemeroteca-digital/.

12 Jornal O Combate, de 21/11/1922, p. 1, acessível pela Hemeroteca Digital da Biblioteca Nacional.

13 Jornal Correio Paulistano, de 08/10/1926, p. 8. Acesso Hemeroteca Digital BN.

14 Sobre a prostituição no começo do século ver principalmente o trabalho de Rago.

15 Relatório da Delegacia de Costumes e Jogos relativo a 1928 publicado na íntegra no dia 23/01/1929, no jornal Correio Paulistano, p. 4. Acessível na Hemeroteca Digital da Biblioteca Nacional: bndigital.bn.br/ hemeroteca-digital/.

16 Decreto n. 3828, de 25 de março de 1925.

17 Trata-se do Relatório do Gabinete de Investigações relativo ao ano de 1936 da Secretaria de Negócios da Segurança Pública, 1937, cuja abreviatura é RELGAB, 1936.

18 Vale lembrar que os mendigos verdadeiros eram mandados desde o início do século para o Asilo dos Inválidos do Guapira, que era uma instituição criada pela Santa Casa. Tal prática era regulamentada pelos artigos 
94 e 95 do Decreto n. 2215, de 15 de março de 1912, que estabeleciam que assim que fossem encontrados mendigos nas ruas eles seriam levados à autoridade policial e em seguida submetidos a exame médico. Conforme o artigo 95, "se após esse exame, forem reconhecidos inábeis para trabalhar, por defeito físico ou moléstia crônica, do que será lavrado o respectivo atestado, os mendigos serão apresentados ao delegado auxiliar, diretor da assistência policial, para que este providencie imediatamente sobre a sua internação no Asilo de Inválidos de Guapira, fazendo-os acompanhar de uma guia (modelo n. 17), dirigida ao respectivo mordomo e instruída com atestado médico".

19 Micheiro era o nome atribuído ao indivíduo que se especializava no furto ou roubo a residências e estabelecimentos comerciais mediante o uso de chaves falsas, as "michas".

\section{REFERÊNCIAS BIBLIOGRÁFICAS}

ALMEIDA JR. João Mendes de. O processo criminal brazileiro. 3a ed. Rio de Janeiro: Typ. Baptista de Souza, 1920, 2 vols.

ALVAREZ, Marcos C. Bacharéis, criminologistas e juristas: saber jurídico e a nova Escola Penal no Brasil. São Paulo: IBCCRIM, 2003.

SALLA, Fernando \& SOUZA, Luís Antônio F. A sociedade e a lei: o Código Penal de 1890 e as novas tendências penais na Primeira República. Justiça \& História, 3(6):97-130, 2003.

BRETAS, Marcos Luiz. Ordem na cidade: o exercício cotidiano da autoridade policial no Rio de Janeiro - 19071930. Rio de Janeiro: Rocco, 1997.

CHALHOUB, Sidney. Trabalho, lar e botequim: o cotidiano dos trabalhadores do Rio de Janeiro na Belle Epoque. São Paulo: Brasiliense, 1986.

CNPq - Relatório Final. A modernização do sistema de Justiça Criminal na região de Bragança Paulista, 18901940. Projeto CNPq - Edital MCT/CNPq - 02/2006 - Universal: Processo 475915/2006-2.

FAUSTO, Boris. Crime e cotidiano: a criminalidade em São Paulo (1880-1924). São Paulo: Brasiliense, 1984.

FOUCAULT, Michel. Surveiller et punir. Naissance de la prision. Paris: Éditions Gallimard, 1975.

FONSECA, Guido. Crimes, criminosos e criminalidade em São Paulo: 1870-1950. São Paulo: Ed. Resenha Tributária, 1988.

GONÇALVES, Flávia Maíra de Araújo. Cadeia e correção: sistema prisional e população carcerária na cidade de São Paulo (1830-1890). São Paulo: Annablume/Fapesp, 2013.

KOERNER, Andrei. 0 impossível panóptico tropical-escravista: práticas prisionais, política e sociedade no Brasil do século XIX. Revista Brasileira de Ciências Criminais, n. 35, jul./set, 2001.

. Punição, disciplina e pensamento penal no Brasil do século XIX. Lua Nova, 68:205-242, 2006.

KOWARICK, Lúcio (1987) Trabalho e vadiagem - a origem do trabalho livre no Brasil. São Paulo: Brasiliense.

MARTINS, Silvia Helena Zanirato. Artífices do ócio: mendigos e vadios em São Paulo (1933-1942). Tese de Doutorado em História, UNESP, 1996. 
MELLO E SOUZA, Laura de. Desclassificados do ouro: a pobreza mineira no século XVIII. Rio de Janeiro: Graal, 1982.

MELOSSI, Dario, PAVARINI, Massimo. Carcel y fabrica: las orígenes del sistema penitenciário (siglos XVI XIX). México: Siglo XXI, 1985.

MISSE, Michel.Crime e violência no Brasil contemporâneo. Estudos de sociologia do crime e da violência urbana. Rio de Janeiro: Lumen Juris, 2006.

MOTTA, Candido N.N. A justiça criminal na capital do Estado de S. Paulo - Relatorio apresentado ao Dr. Procurador geral em 31 de dezembro de 1894. São Paulo: Typ. a Vapor Espindola, Siqueira \& Comp, 1895.

RAGO, Margareth. Os prazeres da noite: prostituição e códigos da sexualidade feminina em São Paulo (18901930). São Paulo: Paz e Terra, 2008.

ROSEMBERG, André. Ordem e burla: processos sociais, escravidão e justiça em Santos. São Paulo: Alameda, 2006.

SALLA, Fernando. As prisões em São Paulo: 1822-1940. São Paulo, Annablume/Fapesp, 1999.

SOUZA, Luís Antônio Francisco de. Lei, cotidiano e cidade: polícia civil e práticas policiais na São Paulo republicana (1889-1930). São Paulo: IBCCRIM, 2009.

TEIXEIRA, Alessandra. Construir a delinquência, articular a criminalidade. Um estudo sobre a gestão dos ilegalismos na cidade de São Paulo. Tese de doutoramento em Sociologia, FFLCH-USP, São Paulo, 2012.

VIANNA, Adriana de Resende B. O mal que se adivinha. Polícia e menoridade no Rio de Janeiro, 1910-1920. Rio de Janeiro: Arquivo Nacional, 1999.

\section{FONTES}

A Estatística policial-criminal do Estado de São Paulo, volume I. Ano de 1938. São Paulo: Tipografia do Gabinete de Investigações, 1939.

A Estatística policial-criminal do Estado de São Paulo, volume II. Ano de 1939. São Paulo: Tipografia do Gabinete de Investigações, 1940.

A Estatística policial-criminal do Estado de São Paulo, volume III. Ano de 1940. São Paulo: Tipografia do Gabinete de Investigações, 1941.

A Estatística policial-criminal do Estado de São Paulo, volume IV. Ano de 1941. São Paulo: Tipografia do Gabinete de Investigações, 1942.

A Estatística policial-criminal do Estado de São Paulo, volume V. Ano de 1942. São Paulo: Tipografia do Gabinete de Investigações, 1943.

A Estatística policial-criminal do Estado de São Paulo, volume VI. Ano de 1943. São Paulo: Tipografia do Gabinete de Investigações, 1944.

Relatório do Gabinete de Investigações relativo ao ano de 1936. Secretaria de Negócios da Segurança Pública. São Paulo: Tipografia do Gabinete de Investigações, 1937.

Relatório das atividades da Polícia Civil no exercício de 1939, apresentado pelo Chefe de Polícia ao interventor do Estado. Secretaria de Segurança Pública. São Paulo: SSP, 1939. 